\title{
Effect of modified care bundle for prevention of ventilator-associated pneumonia in critically-ill neurosurgical patients
}

\author{
Suphannee Triamvisit', Wassana Wongprasert ${ }^{1}$, Chalermwoot Puttima ${ }^{1}$, Matchima Na Chiangmai ${ }^{1}$, \\ Nawaphan Thienjindakul', Laksika Rodkul', Chumpon Jetjumnong ${ }^{2}$
}

${ }^{1}$ Division of Nursing, Chiang Mai University Hospital, Chiang Mai; ${ }^{2}$ Neurosurgery Unit, Department of Surgery, Faculty of Medicine, Chiang Mai University, Chiang Mai, Thailand

Background: Care bundles for ventilator-associated pneumonia (VAP) have been shown to minimize the rate of VAP in critically ill patients. Standard care bundles may need to be modified in resource-constrained situations. The goal of this study was to see if our modified VAP-care bundles lowered the risk of VAP in neurosurgical patients.

Methods: A prospective cohort study was conducted in mechanically ventilated neurosurgical patients. The VAP bundle was adjusted in the cohort group by increasing the frequency of intermittent endotracheal tube cuff pressure monitoring to six times a day while reducing oral care with $0.12 \%$ chlorhexidine to three times a day. The rate of VAP was compared to the historical control group.

Results: A total of 146 and 145 patients were enrolled in control and cohort groups, respectively. The mean age of patients was $52 \pm 16$ years in both groups ( $\mathrm{P}=0.803)$. The admission Glasgow coma scores were $7.79 \pm 2.67$ and $7.80 \pm 2.77$ in control and cohort group, respectively $(P=0.969)$. VAP was found in nine patients in control group but only one patient in cohort group. The occurrence rate of VAP was significantly reduced in cohort group compared to control group $(0.88 / 1,000$ vs. $6.84 / 1,000$ ventilator days, $\mathrm{P}=0.036)$.

Conclusions: The modified VAP bundle is effective in lowering the VAP rate in critically ill neurosurgical patients. It requires low budget and manpower and can be employed in resource-constrained settings.

Key Words: chlorhexidine; critical care; intubation; neurosurgery; oral hygiene; ventilator-associated pneumonia

\section{INTRODUCTION}

Intubated and mechanically ventilated critically ill patients are at a high risk of acquiring ventilator-associated pneumonia (VAP), for those who have been intubated for more than 24 hours have a 6 - to 21 -fold increased risk of VAP [1]. The overall rate of VAP is 10 to 15 per 1,000 ventilator days and the rate is increasing at a rate of 1 to $3 \%$ every ventilator [2].

A VAP bundle has been shown to reduce the VAP rate and has become the gold standard

\section{Original Article}

Received: July 20, 2021

Revised: September 22, 2021

Accepted: September 23, 2021

\section{Corresponding author}

Chumpon Jetjumnong

Neurosurgery Unit, Department of

Surgery, Faculty of Medicine, Chiang

Mai University, 110 Intawaroros Rd, T.

Sriphum, Muang, Chiang Mai 50200,

Thailand

Tel: +66-5393-5533

Fax: +66-5394-6139

E-mail: chumpon.j@cmu.ac.th

Copyright (C) 2021 The Korean Society of Critical Care Medicine

This is an Open Access article distributed under the terms of Creative Attributions Non-Commercial License (https:// creativecommons.org/li-censes/by-nc/4.0/) which permits unrestricted noncommercial use, distribution, and reproduction in any medium, provided the original work is properly cited. 
of care around the world [3]. Our hospital has also been using a VAP bundle called the Suandok model [4] since 2016, and it consists of six elements of care: (1) head of bed elevation by at least $30^{\circ}$, (2) practicing good hand hygiene, (3) checking residual gastric content before feeding, (4) implementing a ventilator weaning protocol, (5) intermittent monitoring the endotracheal tube (ET) cuff pressure three times a day, and (6) oral care with $0.12 \%$ chlorhexidine four times a day. According to our previous study, using the VAP bundle was proven to be effective in lowering the VAP rate to 13.30 per 1,000 ventilator days [4].

Recently, many institutions have implemented the use of continuous cuff pressure monitoring, and it has also been shown to be superior to intermittent cuff pressure monitoring $[5,6]$. This technique, however, necessitates the use of expensive monitoring equipment, which is not currently available at our institution. Furthermore, we also realized that providing oral care four times a day has a drawback in that it is time-consuming and requires manpower. For these reasons, in a setting with limited resources as in our institution, we have to modify the VAP bundle by increasing the time of ET cuff pressure monitoring to four times a day, while reducing the oral care to three times a day. In this study, we investigated whether our modified VAP bundle is as effective as or better than the previous VAP bundle.

\section{MATERIALS AND METHODS}

This study was approved by the Institutional Research Ethics Committee of Faculty of Medicine, Chiang Mai University (No. SUR-2561-05638, Research ID: NUR-2561-05909, Research ID: 05909).

\section{Setting and Study Design}

A prospective cohort study was done in an eight-bed neurosurgical critical care unit and a nine-bed intermediate care neurosurgical unit.

\section{Inclusion and Exclusion Criteria}

Between November 2018 and June 2020, we enrolled all adult (over 18 years old) neurosurgical patients who met the criteria, which included being intubated and receiving mechanical ventilation for at least 24 hours, having no prior signs and symptoms of pneumonia, no contraindication for head of bed elevation, or a fractured cervical spine, and not being an end-of-life care patient. The modified VAP bundle of care was

\section{KEYMESSAGES}

- Ventilator-associated pneumonia (VAP) care bundles should be implemented in all critically ill neurosurgical patients.

- Our modified VAP care bundle has efficacy in reduction of VAP rate and can be used in settings of limited resources.

given to this cohort. Patients in the control group were those who had been treated in the same critical care unit and met the same criteria between January 2016 and the time when the modified VAP bundle was implemented. Age, diagnosis, and Glasgow coma scale were all matched to the cohort group.

\section{Diagnosis of VAP}

The diagnosis of VAP was made by following the Centers for Disease Control and Prevention criteria (Table 1) $[7,8]$ and confirmed by one of the senior intensive care doctors (CJ).

\section{Intervention}

The modified VAP bundle was adopted in this cohort study by increasing the time of intermittent cuff pressure monitoring to every 4 hours (six times a day). We used a hand pressure gauge manometer to monitor and keep the ET cuff pressure at $20-30 \mathrm{~cm} \mathrm{H}_{2} \mathrm{O}$ (Figure 1). The manometer was directly attached to the ET tube's pilot balloon valve without using a three-way stop cock. If the pressure was less than $20 \mathrm{~cm}$ $\mathrm{H}_{2} \mathrm{O}$, we slowly inflated the manometer bulb until it reached a range of 25 to $30 \mathrm{~cm} \mathrm{H}_{2} \mathrm{O}$. The time of oral care with $0.12 \%$ chlorhexidine was lowered to every 8 hours or three times a day (Table 2). Before feeding, the residual gastric content was always checked, and if it was found to be more than $250 \mathrm{ml}$, the feeding was temporarily withheld for 2 hours, and then resumed when the residual contents fell below $125 \mathrm{ml}$. The standard institutional weaning protocol was followed for daily assessment for weaning from mechanical ventilation. The spontaneous breathing trials and eventual extubation were determined by a senior intensive care doctor.

\section{Data Collection and Statistical Analysis}

Basic clinical characteristics were recorded. Quantitative data were reported as frequency, percentage, and mean \pm standard devaition. Statistical analysis using Fischer's exact probability test for comparison between the group. A nonparametric test 
Table 1. Diagnosis of VAP $[7,8]$

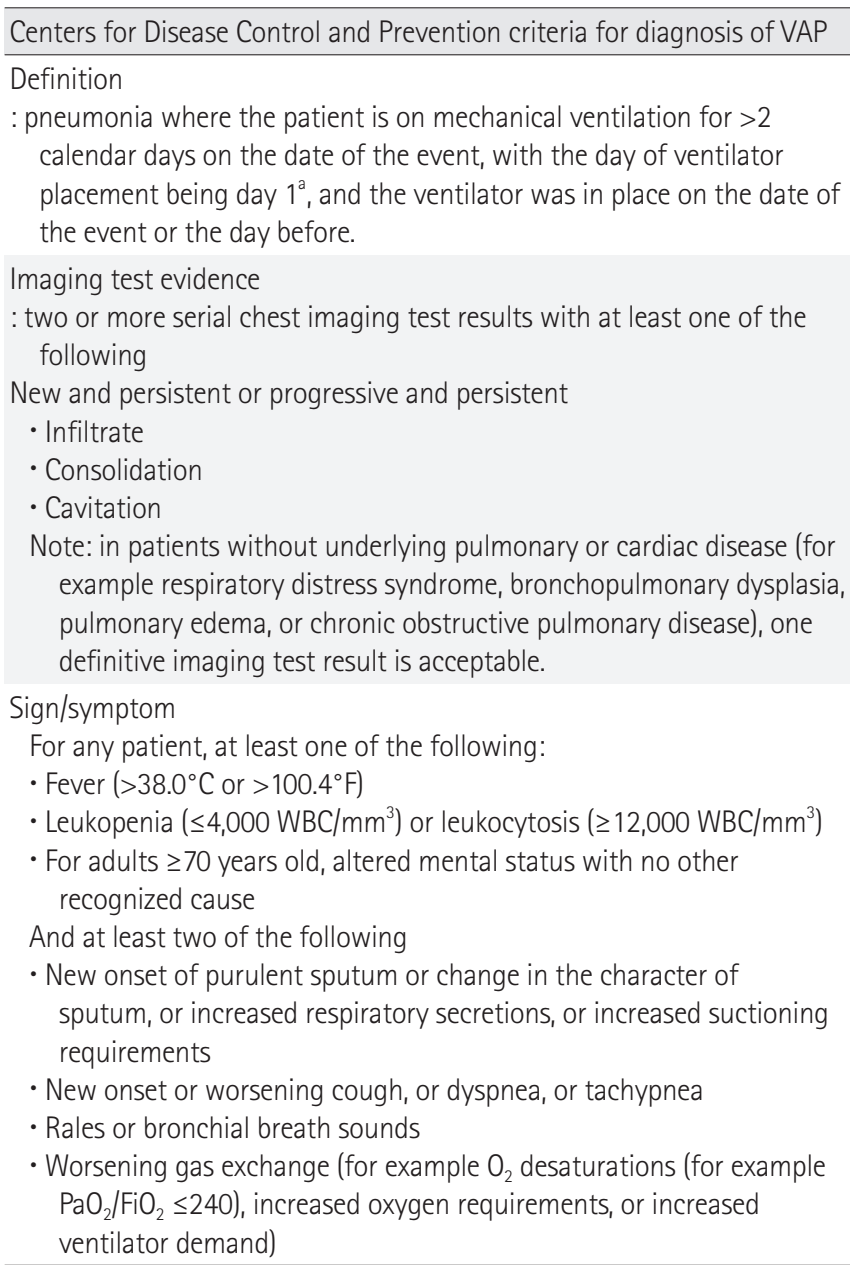

VAP: ventilator-associated pneumonia; WBC: white blood cell; $\mathrm{PaO}_{2} / \mathrm{FiO}_{2}$ : ratio of arterial oxygen partial pressure to fractional inspired oxygen.

af the ventilator was in place before inpatient admission, the ventilator day count begins with the admission date to the first inpatient location.

(Mann Whitney U-test) was used to compare the duration of using mechanical ventilation.

\section{RESULTS}

\section{Patient Demographic Data}

During our prospective cohort between November 2018 and June 2020, A total of 291 patients were enrolled in the study, including 145 patients in the cohort group and 146 patients in the matched control group. In terms of sex, age, admission Glasgow coma score, type of neurosurgery, and comorbidity, there were no significant differences between the two groups. However, the control group had a diagnosis of head injury less than the cohort group ( $41.78 \%$ vs. $56.55 \%, \mathrm{P}=0.033$ ) (Table 3 ).
Table 2. Modification of the VAP bundle

\begin{tabular}{cc}
\hline VAP bundle (control group) & Modified VAP bundle (cohort group) \\
\hline $\begin{array}{c}\text { Intermittently check the ET cuff } \\
\text { pressure every } 6 \text { hours or four }\end{array}$ & $\begin{array}{c}\text { Intermittently check the ET cuff } \\
\text { pressure every } 4 \text { hours or six times }\end{array}$ \\
times a day & a day \\
$\begin{array}{cc}\text { Give oral care with } 0.12 \% & \text { Give oral care with } 0.12 \% \\
\text { chlorhexidine every } 6 \text { hours or } & \text { chlorhexidine every } 8 \text { hours or } \\
\text { four times a day } & \text { three times a day }\end{array}$ \\
\hline
\end{tabular}

VAP: ventilator-associated pneumonia; ET: endotracheal tube.

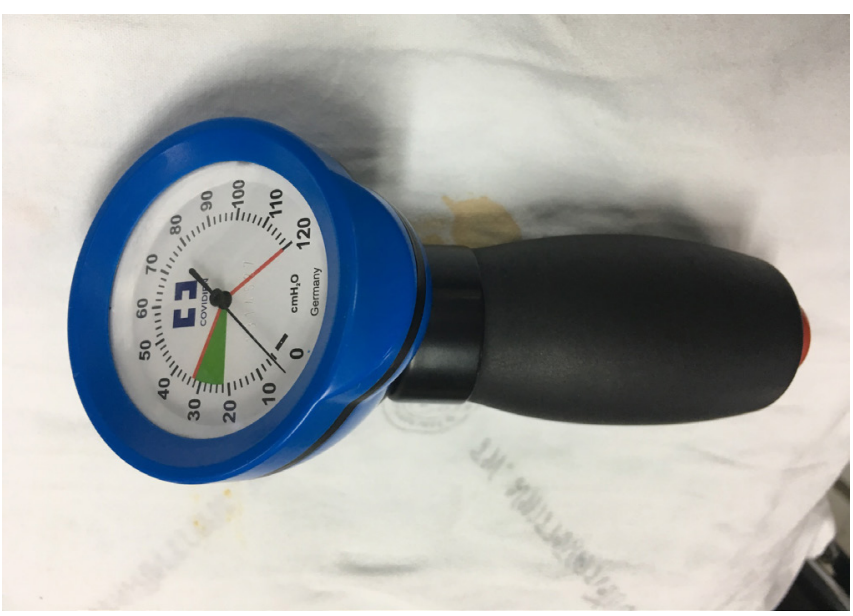

Figure 1. Hand pressure gauge manometer.

\section{Outcomes}

VAP was found in nine patients in control group but just one patient in cohort group. When compared to control group, the rate of VAP was considerably low in cohort group $(0.88 / 1,000$ vs. $6.84 / 1,000$ ventilator days, $\mathrm{P}=0.036)$. Nevertheless, the rates of re-intubation, the day of intubation, and the length of stay were similar in both groups (Table 4).

\section{DISCUSSION}

VAP is a serious hospital-acquired infection that is frequently found in intensive care units. In critically ill neurosurgical patients, it has been associated with recovery and prognosis $[9,10]$. According to Triamvisit et al. [4], the incidence of VAP in the neurosurgical intensive care unit ranged from 7.7 to 27.8 per 1,000 ventilator days. Due to the lack of their normal protective cough mechanism and the reflux of their residual stomach content, intubated patients usually accumulate both normal and abnormal secretion above the ET cuff. The pathogenic microbes are expected to accumulate and proliferate in this secretion, and micro- or macro-aspiration of this secretion 
Table 3. Characteristics of Patients between control group and cohort group

\begin{tabular}{|c|c|c|c|}
\hline Characteristics & $\begin{array}{l}\text { Control group } \\
(n=146)\end{array}$ & $\begin{array}{l}\text { Cohort group } \\
(n=145)\end{array}$ & P-value \\
\hline Gender & & & 0.092 \\
\hline Male & $82(56.16)$ & $96(66.21)$ & \\
\hline Female & $64(43.84)$ & 49 (33.79) & \\
\hline Age (yr) & $52 \pm 16$ & $52 \pm 16$ & 0.803 \\
\hline Admission Glasgow coma score & $7.79 \pm 2.67$ & $7.80 \pm 2.77$ & 0.969 \\
\hline \multicolumn{4}{|l|}{ Diagnosis } \\
\hline Head injury & $61(41.78)$ & $82(56.55)$ & $0.033^{\mathrm{a}}$ \\
\hline Hemorrhagic stroke & $42(28.77)$ & $33(22.76)$ & \\
\hline Brain tumor & $30(20.55)$ & $16(11.03)$ & \\
\hline Infection & $5(3.42)$ & $2(1.38)$ & \\
\hline Others & $8(5.48)$ & 12 (8.28) & \\
\hline Type of neurosurgery & & & 0.149 \\
\hline No neurosurgery & $17(11.64)$ & $34(23.45)$ & \\
\hline Craniotomy & $69(47.26)$ & $67(46.21)$ & \\
\hline Ventriculostomy & $21(14.38)$ & $18(12.41)$ & \\
\hline Craniectomy & $11(7.53)$ & $6(4.14)$ & \\
\hline Burr hole & $8(5.48)$ & $4(2.75)$ & \\
\hline Ventriculoperitoneal shunt & $8(5.48)$ & $5(3.45)$ & \\
\hline Others surgery & $12(8.22)$ & $11(7.59)$ & \\
\hline Comorbidity & & & 0.811 \\
\hline No & $86(58.90)$ & & \\
\hline 1 disease & $36(24.66)$ & & \\
\hline$\geq 2$ diseases & $24(16.44)$ & & \\
\hline
\end{tabular}

Values are prsented as number (\%) or mean \pm standard devaition. ${ }^{a} \mathrm{P}<0.05$.

into the patient's lower respiratory tract can result in VAP [1113]. As a result, any preventive measures to prevent VAP are mandatory in every mechanically ventilated patient.

In our institution, VAP bundle care (Suandok Model) was implemented in 2016 and its effectiveness was reported $[4,14,15]$. As previously stated, the VAP bundle includes two critical components: ET cuff pressure monitoring and oral care [16-20]. Because the ET cuff pressure is affected by several factors including the patient's position or spontaneous loss of pressure over time, it should be monitored and maintained in an appropriate range $\left(20-30 \mathrm{H}_{2} \mathrm{O}\right)$ to avoid underinflation, which can lead to VAP from microaspiration $[6,11,21,22]$. The assessment of cuff pressure by palpation of the ET tube pilot balloon is inaccurate in several studies, hence an intermittent or continuous cuff pressure monitoring device should be used [23]. Despite its superiority, the continuous cuff pressure monitoring device is more expensive and less widely available in
Table 4. VAP, re-intubation, ventilator days, and LOS between control group and cohort group

\begin{tabular}{|c|c|c|c|}
\hline Variable & $\begin{array}{c}\text { Control group } \\
(n=146)\end{array}$ & $\begin{array}{l}\text { Cohort group } \\
\quad(n=145)\end{array}$ & P-value \\
\hline VAP & & & $0.019^{a}$ \\
\hline Yes & $9(6.16)$ & $1(0.69)$ & \\
\hline No & $137(93.84)$ & 144 (99.31) & \\
\hline VAP/1,000 ventilator days & 6.84 & 0.88 & $0.036^{a}$ \\
\hline Re-intubation & & & 0.712 \\
\hline Yes & $15(10.27)$ & $17(11.72)$ & \\
\hline No & 131 (89.73) & $128(88.28)$ & \\
\hline Ventilatorday & $9.01 \pm 8.75$ & $7.72 \pm 7.33$ & 0.513 \\
\hline Percentile (25th, 50th, 75th) & $3,6,12$ & $3,5,9$ & \\
\hline LOS (day) & $15.42 \pm 14.02$ & $11.88 \pm 9.67$ & 0.217 \\
\hline Percentile (25th, 50th, 75th) & $6,11,20$ & $5,9,17$ & \\
\hline
\end{tabular}

most intensive care units. Thus, intermittent cuff monitoring with a hand pressure gauge manometer is a more common practice, especially in the hospital with limited resources. Furthermore, most of the VAP bundle guidelines or other studies that use intermittent cuff pressure monitoring techniques did not specifically state the time or frequency of the cuff pressure monitorings.

In this study, we had proved that our modified VAP bundle, which includes increasing the time of intermittent ET cuff pressure monitoring to every 4 hours (six times a day) and reducing the time of oral care to every 8 hours (three times a day), has comparable or even higher efficacy in reducing the incidence rate of VAP than our old VAP bundle $(0.88 / 1,000 \mathrm{vs}$. $6.84 / 1,000$ ventilator days, $\mathrm{P}=0.036)$. The length of stay was also reduced although it did not show statistical significance (11.88 vs. 15.42 days, $\mathrm{P}=0.217$ ).

Because no study directly reported the VAP rate in patients who received care with intermittent cuff pressure monitoring, so we used indirect evidence in comparison of our results to the others. According to Nseir et al. [11], the VAP rate in the continuous and the intermittent cuff monitoring group was $9.8 \%$ and $26.2 \%$, respectively, while the incidence rate of VAP was 22 per 1,000 ventilator days in the intermittent cuff monitoring group, which is much higher than our result. Similar to Lorente et al. [5], they reported a lower VAP rate in the continuous and the intermittent cuff monitoring group (22.0\% vs. $11.2 \%, \mathrm{P}=0.02$ ). Additionally, his study showed the benefit of using an ET with a small-bore lumen for subglottic secretion 
drainage. In a series of 144 traumatic brain injury patients, Jovanovic et al. [24] reported the VAP rate that as high as $49.7 \%$. This appears to be in contrast to our findings, which showed the VAP rate of only $0.69 \%$ after the modified VAP bundle was implemented.

Regarding oral care, a meta-analysis has shown that oral care with $0.12 \%$ chlorhexidine had the best efficacy, in terms of its cost, adverse reactions, and drug resistance for preventing VAP [25-27] The present study showed that reducing oral care from four to three times a day did not affect the VAP bundle's efficacy. This result was similar to findings from other studies, in which the frequency of oral care ranges from two to four times a day [20,28-31]. An unreported survey of our nursing staff yielded a favorable response in terms of reduced manpower and a cost savings. However, the reason why three times a day oral care is sufficient for lowering VAP remains unknown. Therefore, a quantitative comparison of the amount of microorganisms accumulated in oral or subglottic secretion should be investigated further.

Our study, however, has several limitations, including the following: (1) The historical control group may be subject to selection bias and non-compliance, (2) the results in this study can not extrapolate that our intermittent cuff monitoring technique is as effective as continuous pressure monitoring, (3) the surprisingly low VAP rate in the cohort group could be explained by the rigorous policy of following the modified VAP bundle, (4) the cuff pressure should be measured by trained personnel, and the manometer should be re-calibrated regularly, (5) the period of cuff under-inflations was not documented in our study, which could lead to overclaiming results and finally, although, we purpose that our modified VAP bundle has acceptable efficacy and could be a viable option for a hospital with limited resources, a randomized controlled trial that directly comparing continuous cuff monitoring to modified VAP bundle should be done if possible in the future.

In critically ill neurosurgical patients, the modified VAP bundle has been shown to reduce the VAP rate. In hospitals with limited resources, it can be used as an alternative to continuous cuff pressure monitoring. Further study is needed to compare its efficacy to continuous cuff monitoring.

\section{CONFLICT OF INTEREST}

No potential conflict of interest relevant to this article was reported.

\section{ACKNOWLEDGMENTS}

We thank Ms. Ruth Leatherman (Research Administration Section, Faculty of Medicine, Chiang Mai University) for english language editing.

\section{ORCID}

Chumpon Jetjumnong https://orcid.org/0000-0001-9740-5220

\section{AUTHOR CONTRIBUTIONS}

Conceptualization: ST, CJ. Data curation: WW, CP, MNC, NT, LR. Formal analysis: ST, CJ. Methodology: ST, CJ. Project administration: CJ. Visualization: ST, CJ. Writing-original draft: CJ, ST. Writing-review \& editing: CJ, ST.

\section{REFERENCES}

1. Rello J, Ollendorf DA, Oster G, Vera-Llonch M, Bellm L, Redman R, et al. Epidemiology and outcomes of ventilator-associated pneumonia in a large US database. Chest 2002;122:211521.

2. Craven DE. Epidemiology of ventilator-associated pneumonia. Chest 2000;117(4 Suppl 2):186S-187S.

3. Martin-Loeches I, Rodriguez AH, Torres A. New guidelines for hospital-acquired pneumonia/ventilator-associated pneumonia: USA vs. Europe. Curr Opin Crit Care 2018;24:347-52.

4. Triamvisit S, Maneewan C, Bunturat P, Wongprasert W, Limpassatan K, Kasatpibal N, et al. Results of an evidence-based care bundle for reducing ventilator-associated pneumonia (VAP) in neurosurgical patients. J Med Assoc Thai 2016;99: 1014-9.

5. Lorente L, Lecuona M, Jiménez A, Lorenzo L, Roca I, Cabrera J, et al. Continuous endotracheal tube cuff pressure control system protects against ventilator-associated pneumonia. Crit Care 2014;18:R77.

6. Rouzé A, Jaillette E, Nseir S. Continuous control of tracheal cuff pressure: an effective measure to prevent ventilator-associated pneumonia? Crit Care 2014;18:512.

7. Magill SS, Klompas M, Balk R, Burns SM, Deutschman CS, Diekema D, et al. Developing a new, national approach to surveillance for ventilator-associated events. Crit Care Med 2013;41:2467-75.

8. Magill SS, O'Leary E, Janelle SJ, Thompson DL, Dumyati G, Nadle J, et al. Changes in prevalence of health care-associated 
infections in U.S. hospitals. N Engl J Med 2018;379:1732-44.

9. Li Y, Liu C, Xiao W, Song T, Wang S. Incidence, risk factors, and outcomes of ventilator-associated pneumonia in traumatic brain injury: a meta-analysis. Neurocrit Care 2020;32:272-85.

10. Kourbeti IS, Vakis AF, Papadakis JA, Karabetsos DA, Bertsias G, Filippou M, et al. Infections in traumatic brain injury patients. Clin Microbiol Infect 2012;18:359-64.

11. Nseir S, Zerimech F, Fournier C, Lubret R, Ramon P, Durocher A, et al. Continuous control of tracheal cuff pressure and microaspiration of gastric contents in critically ill patients. Am J Respir Crit Care Med 2011;184:1041-7.

12. Hamilton VA, Grap MJ. The role of the endotracheal tube cuff in microaspiration. Heart Lung 2012;41:167-72.

13. Vallés J, Artigas A, Rello J, Bonsoms N, Fontanals D, Blanch L, et al. Continuous aspiration of subglottic secretions in preventing ventilator-associated pneumonia. Ann Intern Med 1995;122:179-86.

14. Rosenthal VD, Guzman S, Crnich C. Impact of an infection control program on rates of ventilator-associated pneumonia in intensive care units in 2 Argentinean hospitals. Am J Infect Control 2006;34:58-63.

15. Ferreira CR, de Souza DF, Cunha TM, Tavares M, Reis SS, Pedroso RS, et al. The effectiveness of a bundle in the prevention of ventilator-associated pneumonia. Braz J Infect Dis 2016;20:26771.

16. Jackson L, Owens M. Does oral care with chlorhexidine reduce ventilator-associated pneumonia in mechanically ventilated adults? Br J Nurs 2019;28:682-9.

17. Kharel S, Bist A, Mishra SK. Ventilator-associated pneumonia among ICU patients in WHO Southeast Asian region: a systematic review. PLoS One 2021;16:e0247832.

18. Fortaleza CM, Filho SP, Silva MO, Queiroz SM, Cavalcante RS. Sustained reduction of healthcare-associated infections after the introduction of a bundle for prevention of ventilator-associated pneumonia in medical-surgical intensive care units. Braz J Infect Dis 2020;24:373-9.

19. Marjanovic N, Frasca D, Asehnoune K, Paugam C, Lasocki S, Ichai C, et al. Multicentre randomized controlled trial to investigate the usefulness of continuous pneumatic regulation of tracheal cuff pressure for reducing ventilator-associated pneumonia in mechanically ventilated severe trauma patients: the AGATE study protocol. BMJ Open 2017;7:e017003.

20. Segers P, Speekenbrink RG, Ubbink DT, van Ogtrop ML, de Mol BA. Prevention of nosocomial infection in cardiac surgery by decontamination of the nasopharynx and oropharynx with chlorhexidine gluconate: a randomized controlled trial. JAMA 2006;296:2460-6.

21. Athiraman U, Gupta R, Singh G. Endotracheal cuff pressure changes with change in position in neurosurgical patients. Int J Crit Illn Inj Sci 2015;5:237-41.

22. Khan MU, Khokar R, Qureshi S, Al Zahrani T, Aqil M, Shiraz M. Measurement of endotracheal tube cuff pressure: instrumental versus conventional method. Saudi J Anaesth 2016;10:428-31.

23. Sultan P, Carvalho B, Rose BO, Cregg R. Endotracheal tube cuff pressure monitoring: a review of the evidence. J Perioper Pract 2011;21:379-86.

24. Jovanovic B, Milan Z, Markovic-Denic L, Djuric O, Radinovic K, Doklestic K, et al. Risk factors for ventilator-associated pneumonia in patients with severe traumatic brain injury in a Serbian trauma centre. Int J Infect Dis 2015;38:46-51.

25. Zhang TT, Tang SS, Fu LJ. The effectiveness of different concentrations of chlorhexidine for prevention of ventilator-associated pneumonia: a meta-analysis. J Clin Nurs 2014;23(11-12):146175.

26. Chlebicki MP, Safdar N. Topical chlorhexidine for prevention of ventilator-associated pneumonia: a meta-analysis. Crit Care Med 2007;35:595-602.

27. Chacko R, Rajan A, Lionel P, Thilagavathi M, Yadav B, Premkumar J. Oral decontamination techniques and ventilator-associated pneumonia. Br J Nurs 2017;26:594-9.

28. DeRiso AJ 2nd, Ladowski JS, Dillon TA, Justice JW, Peterson AC. Chlorhexidine gluconate $0.12 \%$ oral rinse reduces the incidence of total nosocomial respiratory infection and nonprophylactic systemic antibiotic use in patients undergoing heart surgery. Chest 1996;109:1556-61.

29. Fourrier F, Cau-Pottier E, Boutigny H, Roussel-Delvallez M, Jourdain M, Chopin C. Effects of dental plaque antiseptic decontamination on bacterial colonization and nosocomial infections in critically ill patients. Intensive Care Med 2000;26:123947.

30. Houston S, Hougland P, Anderson JJ, LaRocco M, Kennedy V, Gentry LO. Effectiveness of $0.12 \%$ chlorhexidine gluconate oral rinse in reducing prevalence of nosocomial pneumonia in patients undergoing heart surgery. Am J Crit Care 2002;11:567-70.

31. Scannapieco FA, Yu J, Raghavendran K, Vacanti A, Owens SI, Wood K, et al. A randomized trial of chlorhexidine gluconate on oral bacterial pathogens in mechanically ventilated patients. Crit Care 2009;13:R117. 